\title{
KAPASITAS PENGASUHAN ORANGTUA DAN FAKTOR-FAKTOR PEMUNGKINNYA PADA KELUARGA MISKIN PERKOTAAN
}

\author{
Pinkan Margaretha Indira \\ Fakultas Psikologi Universitas Kristen Krida Wacana \\ pinkan.margaretha@ukrida.ac.id
}

\begin{abstract}
Increased parenting capacity reduces the negative impact of poverty on children. The study aims to capture parental capacity and its enabling factors. A qualitative descriptive approach (interview, observation and time-use diary) is used. Participants obtained through case specific sampling amounted to 4 people. Data is processed with initial and pattern coding. Data credibility using triangulation method. Found participants still have the resources and opportunities to perform childcare functions for children at a minimal level, but their use is not yet optimal. The nutritional adequacy of children has not been a priority. Potential physical and social hazards are realized, but only anticipated for physical harm. Emotional closeness in children tends to spoil, not yet balanced with consistent discipline, moral education submitted to religious institutions. School is important, but parents are constrained to accompany children to learn. There is great social support and neighbors in raising children. Also discussed the suggestion to improve parenting capacity.
\end{abstract}

Keywords: enabling factors, parenting capacity, poor urban families

\begin{abstract}
Abstraksi. Peningkatan kapasitas pengasuhan orangtua mengurangi dampak negatif kemiskinan pada anak. Penelitian bertujuan memotret kapasitas orangtua dan faktor-faktor pemungkinnya. Mengunakan pendekatan studi kasus (wawancara, pengamatan dan timeuse diary). Partisipan diperoleh melalui case specific sampling berjumlah 4 orang. Data diolah dengan initial dan pattern coding. Kredibilitas data menggunakan method triangulation. Ditemukan partisipan masih memiliki sumber daya dan kesempatan untuk menjalankan fungsi pengasuhan bagi anak pada taraf minimal, tetapi penggunaannya belum optimal. Kecukupan gizi anak belum menjadi prioritas. Potensi bahaya fisik dan sosial disadari, tetapi baru dilakukan antisipasi untuk bahaya fisik. Kedekatan emosional pada anak cenderung memanjakan, belum diimbangi dengan disiplin konsisten, pendidikan akhlak diserahkan pada institusi agama. Sekolah adalah hal penting, tetapi orangtua terkendala mendampingi anak belajar. Ada dukungan sosial keluarga besar dan tetangga dalam membesarkan anak. Dibahas juga saran meningkatkan kapasitas pengasuhan orangtua.
\end{abstract}

Kata kunci: faktor-faktor pemungkin, kapasitas pengasuhan orangtua, keluarga miskin perkotaan

\section{PENDAHULUAN}

Kemiskinan masih menjadi permasalahan pembangunan bangsa Indonesia. Indikator angka kemiskinan nasional belum mencapai target MDG's Indonesia tahun 2015 (Bappenas, 2015). Untuk perkotaan, pada bulan Maret 2015 di DKI Jakarta masih terdapat 398,92 ribu orang tergolong miskin (BPS DKI Jakarta, 2015). Umumnya kemiskinan ditinjau dari pendekatan ekonomi. Tetapi Stamboel (2012) dan Suyanto (2013b) mengemukakan bahwa kemiskinan perlu ditinjau dari perspektif multidimensi. Aspek kesehatan, pendidikan, mentalitas, perlu diperhitungkan untuk memahami kemiskinan secara komprehensif.

Di perkotaan, masyarakat miskin ditandai dengan kepala keluarga bekerja di sektor informal, pendidikan rendah, tinggal di pemukiman kumuh rawan bencana, tidak memiliki jaminan kepemilikan rumah yang kuat, dan jumlah anggota keluarga yang lebih banyak daripada masyarakat yang 
tidak miskin. Situasi kemiskinan keluarga tersebut berdampak pada tumbuh kembang anak-anaknya. Hasil penelitian Suyanto (2013) menunjukkan bahwa anak-anak miskin di perkotaan terancam marginalisasi, eksploitasi dan tidak bermasa depan, karena rawan putus sekolah, tidak mendapat bantuan ketika mengalami kesulitan akademik, kurang apresiasi orangtua terhadap pendidikan, dan terpaksa bekerja mencari nafkah.Kemiskinan juga memiliki efek negatif yang signifikan terhadap penyelesaian pendidikan hingga tingkat SMP; kemampuan skolastika memang tidak berperan menjamin terselesaikannya SMP tetapi merupakan faktor penting untuk meningkatkan kesempatan anak lulus dari SMA (Suryadarma dan Suryahadi, 2013). Situasi-situasi tersebut merupakan bentuk pelanggaran hak anak untuk memperoleh pengasuhan dan pendidikan yang mengoptimalkan potensi mereka sehingga berpeluang meraih masa depan.

Kesulitan ekonomi merupakan tekanan yang menambah beban mental orangtua sehingga dapat mempengaruhi kesehatan mental orangtua (Chaffin et.al.1996 dalam Ward, Brown, Hyde-Dryden, 2014). Keluarga miskin menghadapi tekanan ekonomi sehingga menciptakan level stres yang tinggi pada orangtua, yang kemudian tertumpahkan pada hubungan pernikahan dan peran sebagai orangtua (Magnuson dan Votruba-Drzal, 2009). Kualitas pengasuhan orangtua merupakan hal yang krusial bagi perkembangan anak, dimana faktor-faktor resiko karena situasi sosial ekonomi dapat dimediasi oleh kualitas tersebut (Armstrong, BirnieLefcovitch, \& Ungar, 2005).

Hasil-hasil penelitian berikut menunjukkan pentingnya peran dan keterlibatan orangtua terhadap prestasi akademik anak (Chang, Park, Singh, \& Sung, 2009; Rogers, Theule, Ryan, Adams, \& Keating, 2009; Desforges \& Abouchaar, 2003; Fan
\& Chen, 2001), terhadap perkembangan keterampilan dan pengetahuan anak, serta efikasi diri untuk sukses di sekolah (Hoover-Dempsey \& Sandler, 1995), terhadap efikasi diri akademik anak (Sophia, 2007), kompetensi belajar dan perilaku anak (Fantuzzo, McWayne, \& Perry, 2004), serta mengurangi dampak negatif sosial ekonomi rendah pada prestasi akademik anak (Grayson, 2004).

Tak terpenuhinya hak-hak anak karena kemiskinan orangtua dapat diantisipasi dengan meningkatkan keberfungsian orangtua dalam pengasuhan. Keberfungsian orangtua secara konseptual dapat didefinisikan sebagai parenting capacity (kapasitas pengasuhan orangtua). Kapasitas pengasuhan orangtua adalah kemampuan untuk mengasuh anak dengan cara yang 'cukup baik' dalam jangka panjang (White, 2005). Kapasitas pengasuhan tersebut dapat berfungsi efektif jika orangtua memiliki faktor-faktor pemungkin terjadinya pengasuhan yaitu sumber-sumber daya dan kesempatan untuk berinteraksi dengan anak (Hoghhughi, 1997 dalam White, 2005).

Menurut Framework for the Assessment of Children in Need and their Families yang digunakan oleh Departemen Kesehatan di United Kingdom (White, 2005) kapasitas pengasuhan orangtua meliputi 6 dimensi yaitu basic care, ensuring safety, emotional warmth, stimulation, guidance and boundaries, dan stability. Sedangkan faktor-faktor pemungkinnya adalah sumber-sumber daya (situasi sosialekonomi, situasi rumah tinggal), dan waktu keluarga(kuantitas dan kualitas waktu orangtua berinteraksi dengan anak).

Upaya peningkatan keberfungsian orangtua keluarga miskin perkotaan perlu dimulai dari adanya gambaran mengenai kekuatan dan kelemahan orangtua pada 6 dimensi kapasitas pengasuhan orangtua berikut faktor-faktor pemungkinnya. 
Mengingat konteks kemiskinan di Indonesia sebagai negara berkembang tentu tidak setara jika dibandingkan dengan negara maju seperti United Kingdom, maka framework kapasitas pengasuhan orangtua tidak serta merta diukurkan pada orangtua keluarga miskin di Indonesia, tetapi digunakan sebagai kerangka awal mengarahkan penggalian data.

Peneliti melakukan studi kasus pada satu wilayah miskin perkotaan di daerah Jakarta Barat, yaitu kampung Guji Baru. Daerah ini terletak di kelurahan Duri Kepa, kecamatan Kebon Jeruk, kota Jakarta Barat. Menempati lahan sengketa seluas 4 hektar, di tepian kali Sekretaris, dihuni sekitar 2000 kepala keluarga dari berbagai daerah dan etnis. Secara administratif terbagi menjadi $4 \mathrm{RT}$, yang seluruhnya termasuk dalam wilayah RW 2 kelurahan Duri Kepa. Penduduknya lebih banyak bekerja di sektor informal (pedagang kaki lima, buruh bangunan, buruh cuci gosok, tukang ojek, penjaga parkir, supir angkot, dsb), berpendidikan rendah, kurang peduli pada gaya hidup yang berdampak pada kesehatan fisik, padat dan kumuh, serta dianggap sebagai 'beban sosial' karena membuat profil kelurahan Duri Kepa menjadi kurang baik. Saat penelitian dilakukan telah ada satu lembaga non profit yaitu LSM HORE yang menyelenggarakan program Rumah Pintar (bantuan tutorial belajar, 2 kali semnggu) untuk anak-anak di kampung Guji Baru.

Sebagai penuntun penelitian, dirumuskan pertannyaan penelitian bagaimana kapasitas pengasuhan dan faktor pemungkinnya pada keluarga miskin perkotaan. Tujuan penelitian ini adalah memeroleh gambaran kapasitas pengasuhan orangtua dan faktor-faktor pemungkinnya.

\section{METODE PENELITIAN}

$\begin{array}{ccc}\text { Pendekatan } & \text { kualitatif } & \begin{array}{c}\text { deskriptif } \\ \text { melalui studi }\end{array} \text { kasus. }\end{array}$

pengasuhan orangtua didefinisikan sebagai kemampuan mengasuh anak dengan cara yang 'cukup baik' dalam jangka panjang. Terdiri dari 6 dimensi yaitu perawatan dasar, menjamin keamanan, kehangatan emosional, stimulasi, tuntunan dan batasan, serta stabilitas (Ward, 2014).

Faktor-faktor pemungkin meliputi situasi sosial-ekonomi orangtua (usia, latar belakang pendidikan, pekerjaan, penghasilan, tanggungan, bantuan sosial yang diperoleh); situasi tempat tinggal (status rumah, luas, ada tidaknya sekat, ventilasi, bahan dinding dan lantai, situasi area sekitar rumah, ketersediaan air bersih dan listrik); serta waktu keluarga (waktu orangtua berinteraksi dengan anak berikut kegiatannya).

Teknik case specific sampling (Berg, 2007) digunakan untuk memilih partisipan penelitian ini. Karakteristik partisipan adalah: ibu anak-anak usia sekolah di kampung GB; merupakan pengasuh utama anak; tingkat pendidikan rendah ( $\leq$ SMP); suami bekerja di sektor informal; berpenghasilan rendah (< UMK Jakarta). Diperoleh 4 orang ibu yang bersedia berpartisipasi.

Pengumpulan data dilakukan
dengan wawancara dan obserasi. Panduan wawancara semi terstruktur dan pengamatan (Patton, 2002) digunakan untuk memeroleh data mengenai 6 dimensi kapasitas pengasuhan orangtua dan sumber-sumber daya (situasi sosial ekonomi dan situasi rumah tinggal) sebagai faktor-faktor pemungkinnya. Time-use diary selama 7 hari digunakan untuk memeroleh data tentang kuantitas dan kualitas waktu keluarga. Alat bantu lainnya adalah perekam suara digital dan kamera untuk mengambil gambar untuk membantu proses observasi.

Analisis data dilakukan dengan initial coding dan pattern coding (Saldana, 2013). Pada siklus pertama, data verbatim wawancara dan catatan pengamatan 
dianalisa dengan initial coding berikut dibuat analytic memo. Kemudian analisa dilanjutkan dengan siklus kedua yaitu melakukan pattern coding untuk melihat pola, kategori atau tema yang muncul dari data. Upaya menjamin kredibilitas data dilakukan dengan teknik method triangulation (Patton, 2002). Pada penelitian ini pengecekan dilakukan antara data hasil wawancara dengan data hasil pengamatan.

Data respon dari partisipan yang menunjukkan pemaknaan terhadap ke-6 dimensi kapasitas pengasuhan orangtua berikut faktor-faktor pemungkinnya, kemudian dianalisa dan hasilnya digunakan menjadi acuan dasar pengembangan program intervensi untuk meningkatkan kapasitas orangtua. Data tentang faktor pemungkin diindentifikasi sebagai peluang. Untuk setiap dimensi kapasitas pengasuhan, dilakukan identifikasi kekuatan dan kelemahan orangtua. Intervensi yang diberikan menggunakan peluang dan kekuatan yang ada untuk mengatasi kelemahan terkait fungsi orangtua dalam mengasuh dan mendidik anak-anaknya.

\section{HASIL DAN PEMBAHASAN}

Gambaran situasi sosial ekonomi ke-4 partisipan adalah sebagai berikut. Pendidikan ibu paling tinggi adalah SMP (satu orang), 2 lainnya putus sekolah di SD, dan 1 orang buta huruf. Pendidikan ayah paling tinggi adalah SMK (1 orang), 3 lainnya putus di SMP. Ayah dan ibu bekerja di sektor informal. Jumlah tanggungan keluarga adalah $2-4$ orang anak. Biaya belanja harian bervariasi tergantung ketersediaan uang, berkisar antara 15 hingga 50 ribu.

Sedangkan situasi tempat tinggal partisipan adalah sebagai berikut. Semuanya menghuni kamar kos kontrak bulanan, berukuran kecil $\left(4-6 \mathrm{~m}^{2}\right)$, tanpa sekat, berdinding papan, lantai kayu atau semen, perabotan sederhana, tersedia fasilitas kamar mandi bersama, air bersih dan listrik.

Dari hasil pencatatan time-use diary kepada 4 ibu partisipan selama 7 hari, ditemukan bahwa orangtua memiliki waktu 1 jam di pagi hari dan 3 hingga 4 jam di malam hari untuk berinteraksi dengan anak. Waktu tersebut digunakan untuk merawat anak (memandikan, memberi makan), menemani anak mengerjakan PR, menonton televisi, bermain gadget, mengobrol dengan tetangga.

Pada dimensi perawatan dasar, ditemukan bahwa orangtua masih menyediakan tempat tinggal yang memadai untuk berteduh dari panas dan hujan, memperhatikan kebersihan rumah (menyapu, mengepel rutin), merawat pakaian anak supaya bersih (cuci dan setrika), dan mengusahakan anak tidak kelaparan. Hanya saja orangtua belum memperhatikan kecukupan gizi anak, lebih mengutamakan untuk menuruti keinginan jajan anak seperti es, gorengan, mi instan daripada makanan sehat. Orangtua juga masih belum mengganggap penting pemeriksaan kesehatan tubuh dan gigi anak sehingga belum mengusahakan akses BPJS bagi anak.

Pada dimensi menjamin keamanan anak, orangtua mengetahui potensi bahaya fisik dan sosial yang dihadapi anak. Bahaya fisik seperti kecelakaan di jalan raya saat pergi dan pulang sekolah, sepeda dirampas, tawuran, kebakaran, dan pelecehan seksual; diantisipasi dengan cara berusaha mengantar dan menjemput anak ke sekolah, menitipkan anak ke nenek atau tetangga, bahkan mengajak anak ke tempat kerja. Sementara untuk bahaya sosial seperti diejek, dibohongi teman, perundungan, diajak merokok, minuman keras, narkoba, dan pornografi di internet, belum dapat diantisipasi. Orangtua hanya memberikan nasehat anak tidak ikut-ikutan. 
Pada dimensi kehangatan emosional, orangtua menyatakan dekat dan menyayangi anak dengan cara menemani tidur, merawat setiap hari, dan merespon keinginan anak untuk 'bermanja'. Ibu berusaha sedapat mungkin menuruti keinginan-keinginan anak, misalnya anak ingin jajan, maka jika ada uang, orangtua akan menurutinya. Hanya saja orangtua kemudian menggunakan kedekatan emosi itu sebagai 'ancaman' untuk mengendalikan perilaku anak. Orangtua juga cenderung menuruti anak karena 'kasihan' pada anak.

Untuk dimensi stimulasi, orangtua mengganggap sekolah sebagai hal yang penting bagi masa depan anak. Oleh karena itu mereka mengusahakan fasilitas biaya sekolah melalui KJP atau beasiswa lokal di sekolah. Orangtua juga berusaha mengingatkan anak agar mengerjakan $\mathrm{PR}$, dan mencari bantuan dari tetangga atau kakak tutor di Rumah Pintar untuk mengajari anaknya. Hanya saja orangtua mengalami kesulitan mengajari anak pada level kelas yang sudah tinggi (lebih dari kelas 3 SD). Ada juga orangtua yang akhirnya mengerjakan PR anak, bukan mengajari, supaya anak tidak tertinggal di sekolah.

Terkait pemberikan tuntunan dan batasan untuk membangun karakter anak, orangtua berupaya memberi aturan mengenai sikap dan perilaku sesuai norma kesopanan dan ajaran agama. Mereka mendorong anak untuk mengikuti aktivitas agama (mengaji, sholat, pesantren kilat) dengan harapan akhlak anak akan menjadi baik. Hanya saja orangtua kurang konsisten menerapkan batasan itu (misalnya hari ini dilarang, tetapi keesokannya diperbolehkan); menggunakan figur 'ayah' dan 'kedekatan emosi' sebagai ancaman; serta menggunakan 'omelan', 'kemarahan' jika anak dianggap nakal.
Pada dimensi stabilitas, orangtua dalam keterbatasan yang mereka miliki masih memeroleh dukungan dari keluarga besar (misalnya nenek - kakek, paman) dan juga tetangga kampung. Sehingga dalam situasi darurat, misalnya sama sekali tidak memiliki makanan, orangtua masih dapat meminta bantuan dari orangorang tersebut, tidak dalam bentuk uang, tetapi 'menumpang makan'. Hanya saja stabilitas keluarga rentan jika orangtua bercerai, atau ayah sebagai pencari nafkah utama jatuh sakit, sehingga uang yang dimiliki akan tersedot pada biaya pengobatan.

Berdasarkan data dari ke 4 partisipan (ibu) di kampung Guji Baru mengenai kapasitas pengasuhan orangtua dan faktor-faktor pemungkin terjadinya pengasuhan, peneliti menyimpulkan beberapa hal berikut. Orangtua di kampung Guji Baru memang bekerja di sektor informal dengan pendapatan yang kurang stabil, tetapi mereka masih dapat memenuhi kebutuhan pangan, papan dan sandang anak-anaknya pada taraf minimal. Anakanak mereka tidak harus bekerja membantu orangtua mencari nafkah, bisa bersekolah dan bermain. Orangtua masih memiliki waktu keluarga sekitar 3-4 jam di malam hari, tetapi belum mengisinya dengan kegiatan pengasuhan yang berkualitas misalnya hanya menonton tv.

Kebutuhan mendasar anak yang dipahami orangtua adalah makanan, terutama snack (jajan) agar anak tidak kelaparan dan terpenuhi selera makannya, tetapi kurang memperhatikan kecukupan gizi anak. Uang 'jajan' anak adalah pengeluaran rutin yang diusahakan tersedia. Kebutuhan lainnya adalah pakaian yang layak dan cukup bersih.

Orangtua mengetahui potensi bahaya fisik dan sosial bagi anak. Upaya yang telah dilakukan lebih pada menjaga keamanan anak secara fisik. Misalnya 
menitipkan anak-anak pada kakek-nenek atau tetangga untuk diawasi selama ibu bekerja. Potensi bahaya dari segi pergaulan diketahui oleh orangtua tetapi belum ada upaya lebih jauh daripada menasehati anak untuk tidak terlibat halhal buruk tersebut.

Orangtua khususnya para ibu menyatakan dekat secara emosional dengan anak-anaknya karena merawat sendiri sejak bayi hingga saat penelitian dilakukan. Para ibu cenderung memanjakan anak dengan menuruti keinginan anak, tetapi ketika anak dianggap nakal, maka kedekatan emosi itu menjadi 'ancaman' untuk mengendalikan anak.

Orangtua menyadari bahwa sekolah adalah hal yang penting bagi anak. Upaya yang dilakukan orangtua adalah berusaha mengakses bantuan biaya sekolah. Tetapiorangtua mengalami kesulitan untuk membantu anak belajar materi-materi akademik. Bagi ibu yang buta huruf, ini menjadi kendala yang nyata.

Orangtua meyakini bahwa akhlak anak dapat dibentuk melalui keaktifan mengikuti kegiatan agama seperti mengaji dan sholat. Di rumah, orangtua mengajarkan anak batasan-batasan perilaku tetapi belum memiliki strategi yang efektif untuk membangun disiplin anak.

Orangtua memiliki dukungan sosial dari keluarga besar dan tetangga sekitar kampung Guji untuk membantu ketika orangtua membutuhkan. Hal-hal yang menjadi ancaman terhadap stabilitas keluarga adalah perceraian orangtua danjika ada anggota keluarga yang sakit maka beban ekonomi makin berat untuk biaya pengobatan.

Ditinjau dari faktor-faktor yang memungkinkan terjadinya pengasuhan atau berfungsinya kapasitas pengasuhan yang dimiliki orangtua di kampung Guji Baru, ditemukan bahwa mereka memiliki modal dasar untuk pengasuhan anak yaitu kesempatan (waktu dan ruang), serta sumber-sumber daya sosial ekonomi dan tempat tinggal meskipun pada taraf minimal. Akan tetapi belum optimal pemanfaatannya untuk memastikan anak dapat menuntaskan pendidikan hingga tingkat sekolah menengah atas sebagai modal keluar dari siklus kemiskinan keluarga.

Pemanfaatan yang kurang optimal berkaitan dengan kapasitas pengasuhan orangtua terhadap anak yang masih terbatas pada mengusahakan anak tidak kelaparan, memiliki pakaian dan tempat tinggal, aman dari bahaya fisik, dirawat oleh ibu, dipenuhi keinginannya, taat beragama, serta bersekolah (secara status, belum kualitas). Itulah yang dipahami oleh orangtua sebagai fungsi mengasuh anak. Sehingga sumbersumber daya yang dimiliki orangtua seperti waktu dan uang - dialokasikan untuk hal-hal tersebut.

$\begin{array}{clr}\text { Orangtua } & \text { tidak } & \text { memilik } \\ \text { pemahaman yang } & \text { memadai } & \text { tentang } \\ \text { kebutuhan-kebutuhan } & \text { anak } & \text { seperti }\end{array}$ keseimbangan gizi yang menunjang kecerdasan anak, pengecekan kesehatan tubuh dan gigi, keamanan secara sosial dari pengaruh pergaulan buruk, stimulasi yang tepat untuk mengembangkan kemampuan berpikir logis sebagai modal menuntaskan sekolah, batasan dan tuntunan yang konsisten diterapkan sehingga anak memiliki karakter yang dibutuhkan untuk meraih keberhasilan, pengelolaan emosi yang sehat, serta perlunya membuat perencanaan dan pengelolaan sumber daya yang dimiliki agar masa depan anak terjamin. Ketidaktahuan atau wawasan yang terbatas mengenai pengasuhan anak terkait juga dengan latar belakang pendidikan orangtua yang rendah. Kondisi orangtua yang kurang terdidik melemahkan kapabilitas mereka untuk berfungsi sebagai orangtua karena 
kebebasannya terbatasi oleh sempitnya pilihan-pilihan yang dimiliki. Orangtua tidak melihat adanya pilihan selain bekerja mencari uang untuk anak-anaknya.

$$
\text { Sen (2003) mengajukan }
$$

pendekatan kapabilitas yang memandang hidup manusia sebagai suatu set 'doings and beings' atau 'melakukan dan menjadi', sehingga elemen konstitutif hidup manusia adalah keberfungsiannya, yang menentukan kualitas hidupnya. Kekayaan ekonomi adalah salah satu alat untuk meningkatkan kualitas hidup manusia tetapi jika hanya mengupayakan peningkatan ekonomi tanpa keberfungsian, maka tidak akan tercapai hasil akhir yang bernilai. Orangtua keluarga miskin perkotaan mungkin dapat bekerja keras di sektor informal, memperoleh uang untuk memenuhi kebutuhan anak sehingga anak tidak harus bekerja mencari nafkah. Tetapi uang yang diperoleh akan dibelanjakan untuk hal-hal yang bukan kebutuhan esensial bahkan cenderung konsumtif, kalau orangtua tidak 'melakukan' peran atau 'menjadi' orangtua yang sesuai dengan kebutuhan anak-anaknya. Pada akhirnya uang yang diperoleh akan habis tanpa arah jelas, bahkan saat mengalami masalah seperti anggota keluarga sakit, atau tertimpa bencana, orangtua tidak memiliki cadangan sehingga harus berhutang. Akhirnya orangtua tidak juga dapat keluar dari siklus kemiskinan meski sudah bekerja membanting tulang.

Temuan ini sesuai dengan hasil penelitian Suyanto (2013a) pada keluarga miskin perkotaan di Surabaya, yang juga mengembangkan mekanisme 'gali lubang, tutup lubang', cenderung terbelit hutang bunga tinggi, tidak punya tabungan, dan rentan menjadi lebih miskin ketika ada situasi darurat (sakit, bencana). Bertempat tinggal di kota mungkin membuka peluang memperoleh pemasukan yang lebih daripada di desa, asalkan mau bekerja keras. Ini juga menjadi salah satu alasan terjadi perpindahan penduduk dari desa ke kota karena lebih mudah mencari uang di kota. Akan tetapi tanpa wawasan yang memadai, kemampuan berpikir untuk membuat perencanaan masa depan, membedakan kebutuhan dan keinginan, maka uang yang diperoleh akhirnya akan habis tetapi kualitas hidup tidak meningkat.

Artinya tidaklah cukup memahami situasi kemiskinan keluarga di perkotaan hanya dari perspektif ekonomi yang melihat indikator kemiskinan semata-mata dari pendapatan atau pengeluaran yang diperoleh. Modal utama yang perlu dimiliki adalah kapabilitas. Manusia dapat memiliki kapabilitas jika menerima pendidikan baik formal maupun nonformal yang berkualitas. Seperti ungkapan terkenal dari Nelson Mandela bahwa pendidikan adalah senjata paling kuat yang dapat mengubah dunia.

Terbatasnya latar belakang pendidikan orangtua juga memengaruhi kapasitas mereka untuk memberikan stimulasi yang memadai bagi anak-anak terutama dalam mengikuti tuntutan akademis di sekolah. Orangtua cukup puas dengan status anaknya telah terdaftar sebagai siswa di sebuah sekolah formal. Sementara kualitas hasil belajar yang sebenarnya menjadi esensi dari pendidikan justru masih terkendala. Kurangnya kemampuan akademik orangtua karena putus sekolah membuat mereka tidak bisa mendampingi anak belajar di rumah. Jika anak tidak terdampingi dengan baik di level sekolah dasar, maka peluangnya untuk menyelesaikan pendidikan hingga sekolah menengah atas menjadi makin kecil karena anak tidak menguasai kemampuan-kemampuan akademik level dasar. Hal ini sesuai dengan hasil penelitian Suryadarma dan Suryahari (2013) bahwa kemiskinan memberikan efek negatif signifikan terhadap 
penyelesaian pendidikan hingga tingkat SMP.

Pada aspek karakter dan moral anak yang dibentuk melalui adanya tuntunan dan batasan yang jelas dari orangtua, ditemukan bahwa orangtua keluarga miskin perkotaan cenderung 'menyerahkan' pendidikan karakter moral kepada institusi agama atau yang mewakilinya (misal guru mengaji). Keyakinan mereka adalah jika anak rajin sholat dan mengaji maka akan memiliki akhlak yang baik. Kembali lagi dasar keyakinan ini adalah sempitnya wawasan mereka tentang fungsi orangtua. Ketika memiliki anak, orangtua biasanya secara otomatis mempraktekkan cara pengasuhan yang dulu mereka terima dari orangtuanya. Mengharapkan institusi agama mendidik akhlak anak adalah harapan yang tidak realistis. Dari sisi waktu saja, anak lebih banyak menghabiskan waktu dengan keluarga dan bukan institusi agama.

Sementara bahaya sosial berupa pergaulan yang buruk jelas ada di lingkungan kampung Guji Baru. Jika menjelang usia remaja awal anak kemudian tertulari pergaulan buruk (merokok, minuman keras, narkoba, mengamen, berjudi, pornografi) maka itu menjadi ancaman bagi kelancaran studi akademik anak di sekolah. Ketika diperhadapkan pada kesulitan pelajaran, lalu tidak ada bantuan yang signifikan untuk anak dapat mengatasi kendala itu, maka dengan mudah anak berpaling pada kesenangan dan kemudahan yang ditawarkan oleh gaya hidup pemudapemudi di kampung tersebut, yaitu putus sekolah, bekerja di sektor informal (jaga parkir, mengamen, tukang ojek), ataupun menikah di usia muda karena sudah hamil terlebih dulu.

Dalam lingkup yang luas daripada keluarga yaitu komunitas, keluargakeluarga miskin perkotaan biasanya akan terlokalisir di satu daerah pemukiman, beranak-pinak dari generasi ke generasi dan akhirnya membentuk satu komunitas yang cukup memiliki kohesivitas karena merasa bernasib sama. Area pemukiman yang padat membuat jarak sosial menjadi dekat sehingga dapat ditemukan tetangga yang relasinya lebih dekat daripada saudara kandung, serta bisa diandalkan untuk membantu ketika keluarga mengalami krisis. Dalam Framework for the Assessment of Children in Need and their Families (White, 2005), komunitas diperhitungkan juga sebagai salah satu faktor yang mempengaruhi kesejahteraan anak.

Berdasarkan hasil penelitian komunitas warga kampung tersebut cukup kuat ikatan kebersamaannya karena memiliki sejarah berjuang mempertahankan tanah dari incaran mafia tanah. Kohesivitas komunitas ini pun terbawa dalam pengasuhan anak, dimana para orangtua relatif tahu siapa orangtua dari anak-anak yang berkeliaran di kampung, dan bersedia saling menjaga atau mengawasi, sehingga para orangtua menilai lingkungan kampung tersebut cukup menjamin keamanan anak-anak paling tidak secara fisik. Peneliti melihat sense of community tersebut sebagai kapital sosial yang perlu diperhitungkan ketika melakukan intervensi untuk meningkatkan kapasitas pengasuhan orangtua di kampung tersebut.

Salah satu elemen sense of community adalah mutual influence antara anggota-anggotanya sehingga makin kohesif komunitas tersebut maka makin besar tekanan konformitasnya (Kloos, Hill, Thomas, Wandersman, Elias, \& Dalton, 2012). Dengan demikian bagaimana orangtua berfungsi dalam pengasuhan anak juga dipengaruhi oleh kebiasaan orangtua-orangtua lain di kampung Guji Baru. Contohnya jika orangtua lain terbiasa memberi uang jajan anak, lebih suka jajan daripada memasak masakan sehat, maka dengan cepat kebiasaan itu 
akan 'menular' di komunitas itu. Di sisi lain, jika dirancangkan intervensi untuk keluarga-keluarga di kampung Guji, maka perlu dibuat intervensi dengan komunitas sebagai unit intervensinya sehingga penyebaran perubahan akan lebih efektif daripada mengintervensi di level individu atau keluarga saja.

Keterbatasan dari penelitian ini adalah belum diperolehnya data tentang keberfungsian ayah dalam pengasuhan anak di keluarga miskin perkotaan. Perbedaan jender antara peneliti dengan para ayah atau suami partisipan penelitian ini tampak menjadi satu kendala yang belum berhasil ditembus oleh peneliti. Secara normatif di kampung Guji Baru, jika terkait dengan anak maka itu adalah urusan para ibu, bukan ayah. Peneliti juga belum mengeksplorasi lebih jauh mengenai masalah-masalah relasi suami istri yang mungkin menjadi tekanan atau stressor bagi ibu sehingga memengaruhi kapasitas pengasuhannya. Keterbatasan lain terkait dengan framework for the assessment of children in need and their families (White, 2005) yang digunakan sebagai kerangka teori penelitian ini. Tiga unsur framework itu adalah kapasitas pengasuhan orangtua, faktor keluarga dan lingkungan, dan kebutuhan-kebutuhan perkembangan anak. Pada penelitian ini yang sudah terjawab adalah unsur kapasitas pengasuhan orangtua berikut faktor keluarga dan lingkungan sebagai enabling factors. Kebutuhan perkembangan anak belum ditelusuri lebih mendalam karena fokus penelitian ini memang lebih pada fungsi orangtua. Tetapi agar memeroleh pemahaman yang komprehensi, unsur tersebut tentu perlu dan dapat didalami.

\section{SIMPULAN}

Dari paparan hasil dan pembahasan data, diperoleh kesimpulan bahwa orangtua keluarga miskin perkotaan di kampung Guji Baru masih memiliki sumber daya dan kesempatan untuk menjalankan fungsi pengasuhan bagi anak pada taraf minimal, akan tetapi penggunaannya belum optimal karena keterbatasan kapasitas menjalankan peran sebagai orangtua. Kecukupan gizi anak belum menjadi prioritas. Potensi bahaya fisik dan sosial disadari, tetapi baru dilakukan antisipasi untuk bahaya fisik. Kedekatan emosional pada anak cenderung memanjakan, belum diimbangi dengan disiplin konsisten, pendidikan akhlak diserahkan pada institusi agama. Meskipun sekolah dianggap sebagai hal penting bagi anak, tetapi orangtua terkendala mendampingi anak belajar karena keterbatasan kemampuan akademik mereka. Masih ada dukungan sosial keluarga besar dan tetangga dalam membesarkan anak karena rasa kebersamaan yang mereka miliki.

Mengacu pada paparan hasil serta diskusi temuan-temuan penelitian ini, maka peneliti mengajukan saran terkait peningkatan kapasitas pengasuhan orangtua keluarga miskin perkotaan khususnya di kampung Guji Baru yaitu untuk mengembangkan kapabilitas diri sendiri dan keluarganya, orangtua perlu dididik dan dilatih dalam mengelola sumber-sumber daya yang dimilikinya, paling tidak uang dan waktu. Tanpa kemampuan mengelola uang dan waktu maka kerja keras mereka menjadi sia-sia karena tak kunjung memutuskan siklus kemiskinan.

\section{DAFTAR PUSTAKA}

Ajzen, I. (1991). The theory of planned behavior. Organizational Behavior and Human Decision Processes.50, hal 179-211. 
Armstrong, M.I., Birnie-Lefcovitch, S., \& Ungar, M.T. (2005). Pathways between social support, family well being, quality of parenting, and child resilience: what we know. Journal of Child and Family Studies. Vol. 14. No. 2. Hal 269-281.

Badan Pusat Statistik DKI Jakarta. (2015). Tingkat kemiskinan di dki jakarta maret 2015. $\begin{array}{lllll}\text { Diunduh } & \text { pada } & 10 & \text { November } & 2015\end{array}$ http://www.jakarta.go.id/v2/news/2015/09/tingkat-kemiskinan-di-dki-jakarta-maret2015\#.VILmeNIrLMx

Badan Perencanaan Pembangunan Nasional. (2015). Laporan pencapaian tujuan milenium di indonesia 2014. Diunduh pada 10 November 2015 dari http://sekretariatmdgs.or.id/?p=1434

Berg, B. L. (2007). Qualitative research methods for the social sciences (6th ed.). Boston, M.A: Pearson

Chang, M., Park, B., Singh, K. \& Sung, Y.y. (2009). Parental involvement, parenting behaviors, and children's cognitive development in low-income and minority families. Journal of research in childhood education. Vol. 23. No. 3. Hal 309-324.

Desforges, C., \& Abouchaar, A. (2003). The impact of parental involvement, parental support and family education on pupil achievements and adjustment: a literature review. Research Report.

Fan, X., \& Chen, M. (2001). Parental involvement and students' academic achievement: a meta-analysis. Educational Psychology review. Vol. 13, No. 1. hal. 1-22.

Fantuzzo, J., McWayne, C., \& Perry, M.A., (2004). Multiple dimensions of family involvement and their relations to behavioral and learning competencies for urban, low-income children. School Psychology Review, Vol. 33. No. 4. hal 467-480.

Grayson, N.E., (2004). The role of parental involvement in the amelioration of the effects of low sosioeconomic status on academic achievement. Dessertation: Proquest UMI.

Hoover-Dempsey, K.V. \& Sandler, H.M., (1995). Parental involvement in children's education: why does it make a difference?. Teachers College Record. Vol. 97. No. 2.

Hung, A., J. Yoong and E. Brown (2012), "Empowering women through financial awareness and education", OECD Working Papers on Finance, Insurance and Private Pensions, No. 14, OECD Publishing. http://dx.doi.org/10.1787/5k9d5v6kh56g-en

Kloos, B., Hill, J., Thomas, E., Wandersman, A., Elias, M., \& Dalton, J. (2012) Community psychology, linking individuals and communities. USA: Wadsworth Cengage Learning.

Magnuson, K. \& Votruba-Drzal, E. (2009). Enduring influences of childhood poverty. Focus. Vol. 26. No. 2.

Patton, M. Q. (2002). Qualitative research and evaluation methods (3rd ed.). Thousand Oaks, CA: Sage.

Poerwandari (2013). Pendekatan kualitatif untuk penelitian perilaku manusia. Jakarta: LPSP3 UI. 
Rogers, M.A., Theule, J., Ryan, B.A., Adams, G. R., \& Keating, L. (2009). Parental involvement and children school achievement. Canadian Journal of School Psychology.Vol. 24. No. 1. hal 34-57.

Saldana, J. (2013). The coding manual for qualitative researcher. London: Sage.

Sen A. (2003) Development as capability expansion. In: Fukuda-Parr S, et al Readings in Human Development. Readings in Human Development. New Delhi and New York: Oxford University Press

Sophia, M. (2007). Hubungan persepsi anak tentang mekanisme keterlibatan orangtua dalam pendidikan dengan self efficacy akademis. Skripsi: Unika Atma Jaya.

Stamboel, K.A. (2012). Panggilan keberpihakan: Strategi mengakhiri kemiskinan di indonesia. Jakarta: Gramedia Pustaka Utama

Suryadarma, D. \& Suryahadi, A. (2013). The contrasting role of ability and poverty on education attainment: evidence from indonesia. Working Paper. Indonesia: SMERU.

Suyanto, B. (2013a). Perlindungan sosial bagi anak-anak miskin di perkotaan. Jakarta: Child Poverty and Social Protection Conference

Suyanto, B. (2013b). Anatomi kemiskinan dan strategi penanganannya. Malang: In-TRANS Publishing.

Tubbs, C.Y., Roy, K.M., \& Burton, L.M. (2005). Family ties: Constructing family time in low income families. Family Process, 44(1), 397-410

Ward, H., Brown, R., \& Hyde-Dryden, G. (2014). Assessing parental capacity to change when children are on the edge of care: an overview of current research evidence. Research Report. UK: Department of Education.

White, A. (2005). Assessment of parenting capacity. NSW: Centre for Parenting and Research.

Yoder, J.R. \& Lopez, A. (2013). Parent's perception of involvement in children's education: findings from a qualitative study of public housing residents. Children Adolescence Social Work Journal. Vol. 30. Hal 415-433. DOI: 10.1007/s10560-013-0298-0. 